\title{
DIVISÃO SEXUAL DO TRABALHO NO DELITO DE TRÁFICO DE DROGAS
}

\author{
Danielle Coelho Silva ${ }^{1}$ \\ Luciano de Oliveira Souza Tourinho ${ }^{2}$
}

Resumo: Este artigo é um recorte do trabalho de conclusão de curso em Direito e tem como objetivo fazer uma comparação entre a sociedade patriarcal, através da divisão sexual do trabalho, e seu reflexo no mundo do crime, para isso analisando e criticando o crescente encarceramento feminino, principalmente pelo crime de tráfico de drogas. Através do método hipotético dedutivo, buscou-se abordar o movimento feminista e como ele contribuiu para a diferenciação entre sexo e gênero. Posteriormente, tratou-se da divisão sexual do trabalho, que determina papéis sociais diferenciados para homens e mulheres. Por fim, trouxe à tona a reprodução da hierarquia de gênero no delito de tráfico de drogas e como ele contribui para o aumento do encarceramento das mulheres. Ademais, pretende-se mostrar como a lei é falha e a pena exagerada na sua aplicação para essas detentas.

Palavras-chaves: Gênero. Trabalho. Drogas. Encarceramento.

\begin{abstract}
This article is a cut from the course work of the course of law and aims to make a comparison between the patriarchal society through the sexual division of labor and its reflection in the world of crime by analyzing and criticizing the increasing female imprisonment, mainly for the crime of drug trafficking. Through the hypothetical deductive method, we sought to address the feminist movement and how it contributed to the differentiation between sex and gender. Subsequently, it dealt with the sexual division of labor, which determines differentiated roles for men and women.
\end{abstract} Finally, it brought to light the

\footnotetext{
${ }^{1}$ Bacharela em Direito pela UESB, Vice-Presidente da Comissão da Mulher Advogada de Vitória da Conquista e Pós Graduanda em Educação e Diversidade Étnico-Cultural pela UESB.

${ }^{2}$ Doutor em Direito Público pela Universidade Federal da Bahia e professor no curso de Direito da UESB, FAINOR e Faculdade Santo Agostinho.
} 
reproduction of the gender hierarchy in the crime of drug trafficking and how it contributes to the increase in the incarceration of women. In addition, it is intended to show how the law is flawed and the exaggerated penalty in its application to these inmates.

\section{Introdução}

Em razão do grande número de mulheres detidas em sua maioria pelo delito de tráfico de drogas, buscou-se analisar as maneiras de inserção da mulher neste meio criminal diante das representações de gênero típicas do modelo de sociedade patriarcal, que influenciam não só seus modos de participação nas redes do tráfico, mas também sua seleção pelo sistema punitivo formal. Desta forma, a relação entre tráfico de drogas - gênero seletividade penal é o eixo principal desta pesquisa.

Ela se propõe a demonstrar e criticar o recente e crescente encarceramento feminino pelo crime de tráfico de drogas, que a partir do fim da década de 1980 e início da década de 1990, se torna o principal delito no processo de criminalização de mulheres, antes constituído, majoritariamente, por

\section{8}

crimes relacionados à sua condição de gênero, como o aborto, o infanticídio, a prostituição e os crimes passionais.

Tendo como problemática a reprodução do sistema hierárquico de gênero no tráfico de drogas, parte-se da hipótese segundo a qual há uma subalternidade feminina neste delito e que isso contribui para o grande encarceramento feminino. Nesse caminho fazemos uma interface entre o Direito e as Ciências Sociais a partir da categoria analítica de gênero e da atuação do movimento feminista. Para tanto foi realizada uma revisão bibliográfica, com mapeamento e leitura de artigos, livros, dados fornecidos pelo Ministério da Justiça no ano de 2016 e, principalmente, da lei 11.343/06 (BRASIL, 2006).

Destarte, é feita uma diferenciação entre sexo e gênero e a contribuição do movimento feminista na temática. $\mathrm{O}$ feminismo, enquanto corrente ideológica busca a igualdade formal e material entre homens e mulheres. Seus estudos ajudaram na concepção da ideia de gênero, o qual se diferencia de sexo - termo este puramente biológico, enquanto àquele trata-se de uma construção social. Neste sentido, quando os estudos feministas negam o paradigma biológico, rechaçam 
a ideia determinista que mantém determinadas pessoas, conceitos e realizações no mesmo lugar, abrindo caminho para transformações.

Posteriormente, é apresentado o conceito de divisão sexual do trabalho. Esta expressão, que surgiu nos anos 1970, mostra que diante das construções sociais atribuídas a homens e mulheres, há uma divisão do trabalho por gênero também. Aos homens, são direcionados trabalhos relacionados à chefia e espaços públicos, enquanto às mulheres são reservados trabalhos mais ligados ao manual, que envolvem cuidado e espaço privado.

Ademais, no ultimo tópico, explana-se a respeito do crime de tráfico de drogas, ou narcotráfico, principalmente envolvendo as mulheres. O narcotráfico, sendo ramificação da organização criminosa, apresenta características que o define bem. Chamado também de tráfico de drogas, é conceituado como a venda de substâncias ilícitas, sendo, portanto, uma atividade ilegal que absorve um poder paralelo, e com uma economia ilegal, abala a estrutura político-administrativa local, além de gerar uma grande onda de violência e corrupção devido à presença do crime organizado.
Por fim, será mostrado como a desigualdade de gênero está presente nas organizações criminosas. Mesmo no crime, as mulheres ainda exercem funções inferiores, principalmente a de "mulas", isto é, de responsáveis pelo transporte de drogas. Geralmente, às mulheres é relegada essa função porque são vistas como dóceis, "do lar", e incapazes de se envolver com o crime. Quando pegas pelo Estado, mesmo em função subalterna, são associadas como integrantes de uma organização criminosa, imputando-lhes uma pena exacerbada.

\section{Sexo, gênero e patriarcalismo}

Neste tópico, mostrar-se-á a diferenciação entre sexo e gênero. Esta distinção é importante, inicialmente, para apresentar que aquilo que se entende por "papel de homem e papel de mulher" é uma construção histórica e social predominante das sociedades patriarcais, baseada apenas no sexo biológico.

No contexto sociocultural, as relações envolvendo homens e mulheres situam-se na esfera entre a dominação masculina e a opressão feminina. Desta maneira, a realidade de mulheres 
submissas em face do domínio do homem se enraíza em uma ordem social na qual a figura do poder patriarcal é predominante, alicerçado em uma divisão sexual que concede aos homens mais poderes e mais direitos do que às mulheres. Saffiotti (2004: 136) ensina que:

[...] O patriarcado refere-se aos milênios da história mais próxima nos quais se implantou uma hierarquia entre homens $\mathrm{e}$ mulheres, com primazia masculina. Tratar esta realidade em termos exclusivamente do conceito de gênero distrai a atenção do poder do patriarca, em especial como homem/marido, "neutralizando" a exploraçãodominação masculina. Neste sentido, e contrariamente ao que afirma a maioria das(os) teóricas(os), o conceito de gênero carrega uma dose apreciável de ideologia. E qual é esta ideologia? Exatamente a patriarcal, forjada especialmente para dar cobertura a uma estrutura de poder que situa as mulheres muito abaixo dos homens em todas as áreas da convivência humana. É a esta estrutura de poder, e não apenas à ideologia que a acoberta, que o conceito de patriarcado diz respeito. Desta sorte, trata-se de conceito crescentemente preciso, que prescinde das numerosas confusões de que tem sido alvo. [...].

Feminismo é o movimento organizado de mulheres que discutem, reivindicam, contestam e objetivam o fim da opressão e desigualdade entre os sexos, consequente da sociedade capitalista e patriarcal que subalterniza as mulheres. Esse movimento deu os primeiros avanços em direção à busca por igualdade e afirmação da mulher nos espaços públicos e privados, e no desenrolar de sua luta ao longo da história começou a fazer uso do conceito de gênero.

Cumpre destacar a importância do movimento feminista na contestação do determinismo biológico como pressuposto das relações intersubjetivas. Ele objetivou comprovar que as relações entre mulheres e homens, seus papéis sociais, a dominação masculina e a consequente submissão feminina são produtos culturais, portanto, socialmente construídos. Através disso, o movimento contribuiu para a diferenciação entre sexo e gênero.

A noção de gênero é relativamente nova, datada dos anos 1970, fruto do movimento feminista contemporâneo, constituindo-se como um conceito das ciências sociais referente à construção do sexo. Consoante Heilborn (1994 apud NOVAES; MURARI, 2010), implica em afirmar que a palavra sexo ficou vinculada à dimensão anátomofisiológica, enquanto o conceito de 
gênero passou a referir-se às características e papéis culturais atribuídos por aqueles que, na condição de homens ou mulheres, inserem-se numa dada sociedade e numa dada cultura. De acordo com Queiroz (2008 apud COSTA et al., 2012), Stoller foi o primeiro estudioso a utilizar a terminologia gênero, isto em 1968, porém o termo não foi adotado amplamente, tendo maior difusão a partir de 1975 com o clássico texto de Gayle Rubin intitulado "The traffic in women: notes on the political economy of sex", o qual abordou o sistema sexo/gênero.

A partir das críticas ao determinismo biológico e das críticas feministas, na psicologia o conceito de sexo foi substituído pelo conceito de gênero, utilizado atualmente. Essa mudança política tornou-se importante porque deixa de compreender a diferença como determinação biológica, e por isso mesmo, imutável, passando a considerála do ponto de vista psicossocial e, dessa forma, como algo passível de mudança, conforme afirma Hollway (1994, apud NOGUEIRA, 2001). É por meio do gênero que o sujeito se identifica. Dessa forma, a análise do sujeito se faz levando em conta o gênero em que ele está inserido. Para Azeredo (1998 apud
OLIVEIRA; KNÖNEN, 2005), na psicologia, utilizar o gênero faz uma grande diferença, porque permite compreender o sujeito a partir da ideia que ele faz de si mesmo, como homem ou mulher.

Consoante Juliana Santos (2010: 04), as relações de gênero são tão antigas quanto à existência humana, tendo raízes ainda mais profundas do que a formulação do movimento feminista:

[...] De fato, a novidade do conceito é atribuída à construção social que torna desiguais homens e mulheres. Até então, o corpo humano bastava para nos diferenciarmos. A priori, a utilização do conceito apresentou um caráter de contraponto respondendo as interpretações biologistas que vinculam a diferença sexual às posições sociais hierarquicamente diferentes entre mulheres e homens. $\mathrm{O}$ entendimento moderno do mundo mudou esta configuração, principalmente a partir das primeiras tentativas de superação das desigualdades sociais entre homens e mulheres. $[\ldots]$

Segundo Nascimento (2015), a categoria gênero ajuda a entender as complexas manifestações e distribuição de poder em uma sociedade que obedece às hierarquias de classes sociais, etnia e gênero, levando em consideração que o gênero também constrói a identidade de homens e mulheres, ultrapassando as delimitações de papéis sociais. Assim, 
segundo a autora supracitada, as mudanças ocorridas nas relações de gênero possibilitaram uma maior inserção da mulher no espaço público e a construção de um novo perfil feminino que ultrapassa a conduta padronizada de subalternidade e a coloca diante de novas possibilidades e realidades.

Teóricas, como Joan Scott (1989), tratam a categoria gênero em seu aspecto relacional, analisando o caráter social das diferenças entre mulheres e homens. Ela propõe rejeitar os sistemas binários, historicizando e desconstruindo os termos da diferenciação sexual, pois segundo a referida autora, a categoria gênero é apreendida a partir de quatro dimensões: a dimensão simbólica, referente a símbolos culturalmente disponíveis que evocam representações múltiplas (frequentemente contraditórias) - Maria e Eva como símbolo da mulher, por exemplo, na tradição ocidental cristã; a dimensão normativa, que se expressa por intermédio das doutrinas educativa, religiosa, científica, jurídica e política que fundamentam as relações desiguais que definem o masculino e o feminino; a dimensão subjetiva em que as identidades de gênero são construídas a partir da formação de conceitos, imagens e símbolos. Dessa forma, as mulheres e os homens levam consigo uma carga do simbólico, do cultural e do normativo; por fim, a dimensão organizacional, que expressa a forma como se reproduzem os diferenciados papéis sociais de dominação dos homens sobre as mulheres, os quais se enraízam nas formas de pensamento e compreensão da sociedade.

Para a autora Nalu Faria (2006), ao tratar acerca da história das mulheres, embora as mulheres sempre estivessem à frente na defesa de seus direitos e interesses, elas são apresentadas sempre dentro de casa, no espaço privado. Ou quando aparecem à frente das lutas, são relatadas numa relação com o marido ou amante:

[...] A luta das mulheres mostra a sua presença em todas as experiências de lutas e resistência dos povos oprimidos, embora, na maior parte da história, as representações predominantes apresentem as mulheres dentro de casa e sem nenhuma participação pública. No caso da América Latina, aqui e acolá, aparece a figura de mulheres excepcionais. $\mathrm{E}$ quase sempre o relato é que participaram das lutas a partir da relação com um marido ou amante. $\mathrm{Na}$ verdade ainda está oculto que desde as lutas anticoloniais e antiescravidão as mulheres indígenas e negras lutaram ombro a ombro com os homens. É permanente e continuada a presença das mulheres nos processos de luta. Desde a participação já conhecida em processos como a Revolução 
Francesa, em 1789, a Comuna de Paris, a Revolução Russa, etc. (FARIA, 2006: 01).

Os diversos conceitos e diferentes utilizações do termo gênero contribuem para a confusão de seu significado que, de maneira ampla, se referem à noção básica de que aquilo que se entende por masculino e feminino é construído socialmente e não consequência do sexo biológico. Investigar os fenômenos sociais diante da perspectiva de gênero significa adotálo como uma categoria variável da interpretação da realidade, como a classe, etnia, raça, etc., para entender as formas de dominação que derivam de concepções de superioridade do masculino sobre o feminino.

Neste sentido, quando os estudos feministas negam o paradigma biológico, rechaçam a ideia determinista que mantém determinadas pessoas, conceitos e realizações no mesmo lugar, abrindo caminho para transformações. $\mathrm{O}$ androcentrismo - termo ligado às experiências masculinas tidas como universais - passa a ser visto como uma construção, algo que faz parte da cultura, o que significa que a dominação de mulheres por homens não é natural, ontológica e, portanto, pode ser mudada.
Desta forma, a introdução do conceito de gênero na ciência e no mundo representou uma ideia libertadora e revolucionária, pois permitiu ao movimento feminista demonstrar que a opressão sofrida pelas mulheres tinha origem social e cultural, e não raízes biológicas ou genéticas.

\section{Divisão sexual do trabalho}

Depois de falar sobre a importância da distinção entre sexo e gênero para a determinação de papéis socioculturais, neste tópico será abordada a divisão sexual do trabalho e a hierarquia que existe entre os trabalhos masculinos e femininos.

Para Biroli (2018: 21), "Falar de divisão sexual do trabalho é tocar no que vem sendo definido, historicamente, como trabalho de mulher, competência de mulher, lugar de mulher. E claro, nas consequências dessas classificações".

Segundo Souza e Guedes (2016), foi na França, sob o impulso do movimento feminista daquele período durante os anos 1970, que o conceito de divisão sexual do trabalho se consolidou, apesar do mesmo já ter sido objeto de trabalhos em diversos países 
anteriormente. Kergoat e Hirata (2007:

599) o conceituam como sendo:

[...] a forma de divisão do trabalho social decorrente das relações sociais entre os sexos; mais do que isso, é um fator prioritário para a sobrevivência da relação social entre os sexos. Essa forma é modulada histórica e socialmente. Tem como características a designação prioritária dos homens à esfera produtiva e das mulheres à esfera reprodutiva e, simultaneamente, a apropriação pelos homens das funções com maior valor social adicionado (políticos, religiosos, militares etc.).

Para as autoras supracitadas, mais importante que a definição dessa forma de trabalho, é fazer uma distinção entre os princípios e suas modalidades. Elas consideram que há dois princípios organizadores da divisão sexual do trabalho. Um deles é a separação, essa ideia que separa o que é trabalho de homens e de mulheres. Outro é a hierarquia, que considera que o trabalho dos homens vale mais do que o das mulheres:

[...] Se os dois princípios (de separação e hierárquico) encontram-se em todas as sociedades conhecidas e são legitimados pela ideologia naturalista, isto não significa, no entanto, que a divisão sexual do trabalho seja um dado imutável. Ao contrário, ela tem inclusive uma incrível plasticidade: suas modalidades concretas variam grandemente no tempo e no espaço, como demonstraram fartamente antropólogos e historiadores(as). O que é estável não são as situações (que evoluem sempre), e sim a distância entre os grupos de sexo. [...] (HIRATA; KERGOAT, 2007: 599 ss).

$$
\text { Uma das principais }
$$

justificativas ideológicas para a divisão sexual do trabalho, consoante Faria (2011), é a naturalização da desigualdade, que leva para o biológico as construções sociais e as práticas de homens e mulheres. Isso quer dizer que atribui a uma essência biológica, como parte da natureza, a construção do masculino e do feminino.

Contudo, não se pode reduzir o conceito de divisão sexual do trabalho às estatísticas sobre as diferenças de inserção no mercado de trabalho de homens e mulheres. Isso não dá conta da complexidade deste conceito, que faz parte de um processo da luta e da organização feminista, e que busca justamente entender como se transforma em desigualdade $o$ trabalho entre homens e mulheres:

[...] A emergência do conceito da divisão sexual do trabalho teve um papel muito importante para questionar o que era a definição clássica de trabalho. As feministas que discutiram a divisão sexual do trabalho estavam no campo do marxismo. Elas problematizaram que o debate de classe não 
explicava e não dava conta do conjunto da realidade do trabalho. Num primeiro momento, parecia haver uma destinação dos homens ao trabalho chamado produtivo e uma destinação prioritária das mulheres ao trabalho reprodutivo. Todavia, as mulheres estavam simultaneamente nas duas esferas: no trabalho produtivo e no trabalho reprodutivo. [...] (FARIA, 2011: 02).

Como se nota, as mulheres, por muito tempo foram projetadas para o papel secundário a elas relegado, como cuidar dos filhos, da casa e do marido. Isso decorre da construção social de gênero atribuído, nos quais cabe ao gênero feminino o governo do espaço privado, enquanto aos homens o espaço público.

Para Hirata (2010), é necessário estabelecer uma relação entre desigualdade no mercado de trabalho, entre mulheres e homens, assim como desigualdades na família e na esfera doméstica (relação de trabalho, de poder, de saber, relações de dominação). Afinal, considera esta autora, "o trabalho precário é majoritariamente feminino" (2010: 03).

A família é uma das principais responsáveis por apresentar a ideologia do que se espera em uma mulher, transmitindo os ensinamentos e valores culturais de mãe para filha - onde esta começa a se tornar o reflexo daquela - "o que leva à solidificação do papel da mulher como responsável pela conservação e manutenção de determinados valores sociais" (FAVARETTO 2000 apud DUTRA, 2012, p. 3).

De acordo com Biroli (2015), a realização da mulher, em que o casamento tem uma função importante, as coloca numa posição que se desdobra em menor controle sobre suas vidas, menor tempo e participação mais restrita na vida pública, o que implica também renda menor, trabalho precarizado, e mais obstáculos à participação política.

Consoante à mesma autora:

[...] Acompanhando tendências verificadas em outros países latino-americanos, foi nas últimas décadas do século XX que o perfil do acesso das mulheres brasileiras à educação e ao trabalho remunerado se alterou significativamente. Entre 1970 e inicio do século seguinte, o percentual de mulheres economicamente ativas passou de $18,5 \%$ para cerca de $55 \%$, tendo alcançado um teto de $59 \%$ em 2005. (...) Hoje têm, em média, mais tempo de educação formal do que os homens, passando a ser maioria entre as pessoas matriculadas no ensino superior. Apesar disso, a diferença entre o rendimento médio das mulheres e dos homens permanece em torno de $25 \%$, e a profissionalização não garantiu acesso igualitário às diferentes ocupações. [...] (BIROLI, 2018: 21). 
(ou todos aqueles que requerem um

Para Nogueira (2001 apud PRAUN, 2011: 62), a ideologia dominante, por meio de seu discurso construído, partilhado e difundido tanto em nível disciplinar como político, consegue manter uma ordem social que perpetua as desigualdades e o sexismo. Assim, é importante considerar a linguagem desse discurso como elemento fundamental da construção da subjetividade masculina e da feminina, e da manutenção das relações sociais e de poder, para que se possa teorizar a respeito da construção social do gênero.

A inserção das mulheres no mercado de trabalho ainda é bastante injusta e reproduz desigualdades sociais e entre os gêneros, favorecendo a subalternidade feminina que ainda persegue as mulheres não só no trabalho, mas também nos diferentes âmbitos da vida (político e social). Contudo, vale ressaltar a importância da inserção no mercado de trabalho na ruptura da histórica dominação masculina.

A desigualdade entre os sexos ainda vai mais além da divisão sexual entre as profissões. Mesmo quando homens e mulheres exercem a mesma profissão, existe na grande maioria das vezes, a tendência aos cargos de chefia poder maior de decisão), serem assumidos por profissionais do sexo masculino. São oferecidas aos homens mais oportunidades de "carreira" do que às mulheres. Para Cisne (2015: 122), “as atividades e trabalhos desenvolvidos por mulheres, ao serem vistos como atributos naturais, extensões de habilidades próprias do gênero feminino, são consideradas dons e não trabalho".

Segundo Hirata (2002 apud ALBUQUERQUE 2007: 08) existe ainda no seio da divisão do trabalho social e sexual, uma apropriação da esfera tecnológica pelo poder masculino. Deste modo, a autora acima referida defende ser impossível uma abordagem das relações de trabalho sem perceber que existe uma apropriação históricosocial da tecnologia pelos homens.

\section{A representação feminina no crime de tráfico de drogas}

Por fim, depois de apresentada a categoria de gênero, relacionando-a com o patriarcalismo e a divisão sexual do trabalho, neste tópico será abordada tal divisão entre os sexos no delito de tráfico de drogas e como ele contribui para o encarceramento feminino. 
A Lei 11.343/06 é a norma que tipifica o crime de tráfico de drogas (BRASIL, 2006). Com as mudanças decorrentes dela, esperava-se que o número de pessoas presas diminuiria, uma vez que o usuário não seria mais punido com pena de prisão. Contudo, contrariando essa expectativa, o que se viu nos últimos anos foi exatamente o movimento contrário, um aumento do número de presos por tráfico de drogas após 2006. As prisões por esse crime aumentaram na vigência da nova lei e a proporção de presos por tráfico em relação aos outros crimes cometidos vem crescendo neste mesmo período. Em 2006, o sistema penitenciário brasileiro contava com 47.472 pessoas presas por tráfico no país. Já em 2016, registrou-se 176.691 presos por esta razão, de acordo com dados do Departamento Penitenciário Nacional (2017).

\section{Para Boiteux (2009 apud} CHERNICARO, 2014: 104), “o mercado de drogas ilícitas constitui-se como uma atividade lucrativa". Segundo a mesma autora, este contingente é formado principalmente por pessoas jovens, que nunca ocuparam uma vaga no mercado formal e que constituem o grupo social mais vulnerável a ser utilizado pelo tráfico.
No Brasil a população carcerária feminina é pequena quando comparada à masculina. Contudo, se observa um grande aumento dessa participação feminina na criminalidade em geral, especificamente no tráfico de drogas. Em junho de 2016, a população prisional feminina atingiu a marca de 42 mil mulheres privadas de liberdade, o que representa um aumento de $656 \% \mathrm{em}$ relação ao total registrado no início dos anos 2000, quando menos de seis mil mulheres se encontravam no sistema prisional. No mesmo período, a população prisional masculina cresceu 293\%, passando de 169 mil homens encarcerados em 2000 para 665 mil homens em 2016. (INFOPEN MULHER, 2016).

A população feminina, ainda mais que a masculina, inclui uma alta proporção de detentas acusadas ou condenadas com relação às drogas. Consoante o Infopen Mulher (2016), de modo geral, pode-se afirmar que os crimes relacionados ao tráfico de drogas correspondem a $62 \%$ das incidências penais pelas quais as mulheres privadas de liberdade foram condenadas ou aguardam julgamento em 2016, o que significa dizer que três em cada cinco mulheres que se encontram no sistema 
prisional respondem por crimes ligados ao tráfico. Entre as tipificações relacionadas ao tráfico de drogas, o crime de associação para o tráfico corresponde a $16 \%$ das incidências e o crime de tráfico internacional de drogas responde por $2 \%$, sendo que o restante das incidências refere-se à tipificação de tráfico de drogas, propriamente dita.

Em meio aos dados que tratam do perfil da população carcerária feminina, o Infopen Mulher abrange diferentes aspectos os quais permitem visualizar o perfil da mulher encarcerada e as situações de vulnerabilidade social que as envolvem, elencando indicadores sobre a raça/cor/etnia da mulher privada de liberdade, o estado civil, a escolaridade e até dados sobre a razão da prisão, a sua natureza e tipo de regime. Observa-se, nos dados apresentados em 2016, que 45\% das mulheres presas estavam sob custódia do sistema prisional brasileiro sem condenação. Esse número é superior ao índice nacional de pessoas privadas de liberdade sem condenação, que atinge a taxa alarmante de $40 \%$ (INFOPEN, 2016), demonstrando a natureza extremamente punitiva do sistema prisional brasileiro e a utilização exacerbada da pena de prisão como medida sancionatória, até para crimes menos gravosos.

A prisão de mulheres devido ao tráfico, ao que parece, está ligada ao fato destas ficarem em posições de menor importância na rede de tráfico e mais expostas à ação policial. A política da guerra às drogas tem atingido cada vez mais mulheres, e a maioria das presas em Estados com cenários de encarceramento em massa foi condenada ou está sendo processada por situações envolvendo o uso "problemático" ou a venda de drogas. Um dos primeiros pontos a ser considerado é a divisão sexual do trabalho, conceito exposto anteriormente, a qual se acentua de maneira profunda no mercado de drogas ilícitas:

O tráfico de drogas obedece a uma complexa estrutura que segue padrões hierarquizados, envolvendo diferentes graus de participação e importância, o que aponta para "diferentes papéis em suas "redes", desde as atuações mais insignificantes até as ações absolutamente engajadas e com domínio do fato final. (BOITEUX, 2009: 39 apud CHERNICHARO, 2014: 105).

Consoante Fonseca (2000: 44 apud CHERNICHARO, 2014: 107), “a inserção feminina neste delito obedece à distribuição de mão de obra específica e sexuada em cada um dos setores 
produtivos que se fundamentam em representações e crenças a respeito do que deve ser feminilidade e masculinidade". Segundo a autora, quando se atenta para o conjunto de falas que expressam estas crenças, nota-se que, de maneira geral, é imaginado como masculino o que é ligado a máquinas e ao feminino o que é manual, portanto feito com paciência e delicadeza.

Apesar de um ambiente historicamente masculinizado - e construído para e por homens - as mulheres demonstraram-se uma das principais afetadas pelo encarceramento em massa no país, sendo uma parcela significante de sua população a ser enxergada e ouvida, de acordo com as suas peculiaridades e demandas específicas. O Ministério da Justiça, em seu Levantamento Nacional de Informações Penitenciárias (2016), apresenta que as mulheres, no Brasil, representam $6,4 \%$ do total de pessoas em situação privativa de liberdade, estando dentro da margem projetada pelo World Female Imprisonment List - instituto que aponta um índice de 2 a $9 \%$ de mulheres sobre a população prisional mundial, considerando $80 \%$ dos países.

Das mulheres presas por tráfico de drogas, um número ínfimo apresenta um status de comando dentro de alguma organização criminosa. Desta forma, a maioria esmagadora de tais mulheres não são chefes de quadrilha, nem mesmo ocupam funções importantes na rede do tráfico. Elas são mulas, e muitas delas, meros meios de transporte de drogas para o interior de presídios a fim de suprir necessidades de seus companheiros (MENDES, 2014 apud PANCIERI, 2014). Nesse sentido, segundo a autora supracitada, visualiza-se a faceta simbólica da mulher na qualidade de mula; tal como ocorre com o animal mula (e talvez este seja o ponto íntimo da analogia), a mulher cumpre o que manda o seu superior, transporta drogas sem muitas vezes ter qualquer discernimento sobre a atividade desempenhada pelo seu dono.

Chernicaro (2014) entende que a inserção da mulher no tráfico leva em conta a construção social de sua identidade. Atributos de "vulnerabilidade", determinados pelo seu gênero, classe, idade, etc., não só são necessários como fundamentais para que exerçam esta função. Isto significa, corroborando com o ponto de vista da autora supramencionada, que a mulher pelo fato de ser mulher (ou pela construção de gênero socialmente 
atribuído a ela) se encaixa no papel de mula, pois possui as características que possibilitam o exercício deste papel.

Em geral, as mulheres atuam como coadjuvante, enquanto os protagonistas continuam sendo os homens. Dificilmente alguma delas é chefe do tráfico, o que contribui para manter sua posição subalterna e limitando-se quase sempre às funções de: vapor, que é o encarregado do preparo e embalagem, produto para consumo; mula, indivíduos que geralmente não possuem passagens pela polícia e que se aventuram a realizar o transporte da droga; e olheiro, como são chamadas as pessoas que se posicionam em locais estratégicos para vigiar as vias de acesso. (BASTOS, 2011 apud BIANCHINI, 2011). As mulas constituem o último escalão nas dinâmicas do tráfico, além de serem facilmente prescindíveis. Muitas mulheres mulas aceitam realizar o trabalho sem nem haver estabelecido qualquer contato prévio com atividades ilegais. Tais elementos acentuam a imagem da mula como vítimas, removendo a ótica de verdadeiras criminosas (PANCIERI, 2014).

A Lei de Drogas endureceu a criminalização do tráfico, aumentando as penas para tráfico de drogas e associação ao crime organizado, já que são flagradas diretamente com a droga. Por esse motivo, o judiciário praticamente deduz que a pessoa está envolvida no tráfico de drogas, criando obstáculos para o acesso aos benefícios na execução penal (como a progressão de regime). A intensificação da repressão policial às pessoas consideradas traficantes combinada com $\mathrm{o}$ aumento da pena para o tráfico e o endurecimento do regime de cumprimento da pena tem levado ao grande aumento de mulheres nas prisões. No entanto, dentro de uma racionalidade que não leva em consideração as circunstancias reais que corroboram para a mulher mula estar em tal situação.

Uma possível solução para as mulheres pegas exercendo o transporte de drogas, que como foi apresentado, não necessariamente integram uma organização criminosa, é a aplicação do tráfico privilegiado. $\mathrm{O}$ tráfico privilegiado é a diminuição de pena prevista no parágrafo $4^{\circ}$, art. 33 da Lei 11.343/06 (Lei de Drogas) às pessoas condenadas por tráfico de drogas quando forem primárias, tiverem bons antecedentes e não integrarem uma “organização criminosa". Nesses casos, o magistrado poderá aplicar esta causa de 
diminuição e reduzir a pena aplicada. Assim, reconhecido o tráfico privilegiado, a progressão do regime (que é de $2 / 5$ ou $3 / 5$ para os crimes hediondos) será de 1/6, ou seja, a mesma progressão aplicada para crimes comuns.

$\mathrm{Na}$ prática, o fato do crime ser considerado privilegiado implica na previsão de uma pena menor. Muitas pessoas que são condenadas à pena mínima prevista para o tráfico, de cinco anos, ao terem a aplicação desta causa de diminuição tem sua pena reduzida para menos de quatro anos.

Como prevê o art. 44 do Código Penal, quando a pena aplicada não for maior que quatro anos e não houver violência ou grave ameaça, a pena privativa de liberdade poderá ser substituída por uma pena restritiva de direitos. Contudo, alguns juízes têm uma resistência em aplicar o referido beneficio argumentando que pelo fato do crime ser hediondo, há uma gravidade em abstrato implícita.

\section{Conforme Rosa Del Olmo} (1996), as mulheres possuem tipos de participação "esdruxulas" nas redes do tráfico. Segundo esta autora, é muito comum que as mulheres sejam presas pela polícia por colaborarem com um ou mais homens ou familiares como transportadoras, ou por estarem em lugares onde se produzia ou se armazenava produtos ilícitos, razão pela qual se tornava cúmplice e, portanto, criminosa. Além disto, verificam Del Olmo (1996) e Escobar (1991) apud Chernicharo (2014), quando estes lugares são descobertos pela polícia, é comum que só as mulheres estejam (já que assumem as tarefas da casa) e consequentemente sejam as únicas responsáveis pela atividade ilícita que ali ocorria.

Moura (2005 apud BIANCHINI, 2011) afirma que o negócio da droga encontra na esfera doméstica espaço propício para se instalar, já que se estabelece em relações determinadas e não tanto em fachadas de rua. Como o lugar da mulher, historicamente, é o lugar privado, ela encontra neste tipo de atividade atributos essenciais que possibilitam a complementação de sua renda às responsabilidades classicamente demandadas a ela, como o cuidado dos filhos e da casa.

\section{Considerações finais}

O mundo do tráfico, como foi analisado, é machista e costuma objetificar mulheres e relegá-las a 
posições mais dispensáveis. A posição subalterna no tráfico indica maior vulnerabilidade destas mulheres e menor margem de manobra junto à polícia, o que faz com que sejam capturadas mais facilmente pelo poder punitivo formal.

Reconhecer a discriminação de gênero que marca a entrada das mulheres no tráfico de drogas não significa afirmar que as mulheres são meras vítimas de homens ou que não sabem se defender. De todo modo, o que se deve observar é que criminalizar duramente os empregos de pior remuneração dentro do tráfico de drogas é uma opção marcada por uma discriminação de gênero, pois são esses os empregos de que muitas mulheres dependem para a manutenção de suas famílias.

Diante de toda problemática, a grande questão é que se as mulas responderiam pelo crime de trafico de drogas ou a elas aplicariam uma pena mais branda, visto que essas pessoas, primordialmente as mulheres, são absolutamente descartáveis na estrutura do tráfico, bem como servem meramente como meios de transporte, sem possuir o necessário ânimo de comercializar a droga. Assim, não é possível verificar ligações diretas das mulas com o tráfico de drogas, visto que são indivíduos utilizados como meras ferramentas de transporte de droga para dentro do cárcere ou para outros países.

Ademais, deve-se pensar na adoção de políticas públicas bem como de uma política criminal que diferencie essas mulheres das outras categorias de traficantes. Tendo em vista que a mulher mula serve, tão somente, de mero instrumento de transporte, ou ainda, “correio da droga”, não parece razoável que elas possuam o mesmo tratamento legal, ao estarem sujeitas a pena prevista pelo artigo 33 da Lei 11.343/06.

Legislações que diferenciem com critérios realistas e justos são um dos passos fundamentais para reformar o sistema penitenciário e diminuir o encarceramento em massa. Além disso, admitir essa diferenciação no sistema penal brasileiro significaria avançar em direção a uma política pública com viés de gênero, voltada para combater desigualdades e sanar as injustiças sociais.

Observa-se, assim, que o crime organizado (configuração presente em grande parte dos crimes de tráfico de drogas) replica os marcadores de gênero da sociedade em geral. Embora a subordinação feminina tenha diminuído, 
ela permanece existindo também na criminalidade.

\section{Referências bibliográficas}

ALBUQUERQUE, Vivian Matias dos Santos. Divisão sexual do trabalho: complementaridade ou conflito? Revista Urutágua, Maringá, n. 13, ago./nov. 2007.

Disponível

em: http://www.urutagua.uem.br/013/13albu querque.htm. Acesso em: 20 nov. 2017.

BIANCHINI, Alice. Mulheres, tráfico de drogas e sua maior vulnerabilidade: série mulher e crime. Jusbrasil, 2011. Disponível em: https://professoraalice.jusbrasil.com.br/ $\operatorname{artigos} / 121814131 /$ mulheres-trafico-dedrogas-e-sua-maior-vulnerabilidadeserie-mulher-e-crime. Acesso em: 03 jul. 2019.

Levantamento Nacional de Informações Penitenciárias [INFOPEN]. INFOPEN Mulheres. Brasília: Ministério da Justiça e Segurança Pública, Departamento Penitenciário Nacional, 2018.

Levantamento Nacional de Informações Penitenciárias [INFOPEN]. Atualização
- Junho de 2016. Brasília: Ministério da Justiça e Segurança Pública, Departamento Penitenciário Nacional, 2017.

BIROLI, Flávia. Gênero e desigualdades: os limites da democracia no Brasil $-1^{\mathrm{a}}$ ed. São Paulo: Boitempo, 2018.

\section{Uma posição desigual:}

mulheres, divisão sexual do trabalho e democracia. Blog da Boitempo, mar. $2015 . \quad$ Disponível em: https://blogdaboitempo.com.br/2015/03/ 06/uma-posicao-desigual-mulheresdivisao-sexual-do-trabalho-edemocracia/. Acesso em: 20 out. 2018.

CHERNICHARO, Luciana Peluzio. Sobre mulheres e prisões: seletividade de gênero e crime de tráfico de drogas no Brasil. Rio de Janeiro, 2014. 160f. Dissertação (Mestrado em Direito) Faculdade Nacional de Direito, Universidade Federal do Rio de Janeiro. Disponível em: http://www.neip.info/upd_blob/0001/15 65.pdf. Acesso em: 15 jun. 2019. CISNE, Mirla. Gênero, Divisão Sexual do Trabalho e Serviço Social - 2 ed. São Paulo: Outras Expressões, 2015. 
COSTA, Renata Gomes da; SILVERA,

Clara Maria Holanda; MADEIRA, Maria Zelma de Araujo. $\mathbf{1 7}^{\circ}$ Encontro Nacional da Rede Feminista e Norte e Nordeste de Estudos e Pesquisa sobre a Mulher e Relações de Gênero, Brasil, dez. 2012. Disponível em: http://www.ufpb.br/evento/index.php/17 redor/17redor/paper/view/56. Acesso em: 02 jul. 2019.

DUTRA, Thaíse Concolato. A criminalidade feminina com relação ao tráfico de drogas, frente à lei 11.343/06. Disponível em: http://www3.pucrs.br/pucrs/files/uni/po a/direito/ graduacao/tcc/tcc2/trabalhos2012_2/thai se dutra.pdf. Acesso em: 05 set. 2018.

FARIA, Nalu. Por onde passa a história da luta das mulheres. Sempreviva Organização Feminista, mar. 2014. Disponível em: http://www.sof.org.br/2014/03/28/poronde-passa-a-historia-da-luta-dasmulheres/. Acesso em: 05 jun. 2018.

A divisão sexual do trabalho como base material das relações de gênero. Sempreviva Organização Feminista, jun. 2011. Disponível em: http://www.sof.org.br/2011/06/20/a-

divisao-sexual-do-trabalho-como-basematerial-das-relacoes-de-genero/. Acesso em: 20 out. 2018.

HIRATA, Helena. Novas configurações da divisão sexual do trabalho. Revista Tecnologia e Sociedade - $2^{\mathrm{a}}$ ed, 2010. Disponível em: https://periodicos.utfpr.edu.br/rts/article/ view/2557/1661. Acesso em 22 nov. 2018 .

HIRATA, Helena; KERGOAT, Danièle. Novas configurações da divisão sexual do trabalho. Cadernos de Pesquisa, v. 37, n. 132, pp. 595-609, set./dez. 2007. Disponível em: http://scielo.br/pdf/cp/v37n132/a053713

2. Acesso em: 18 ago. 2018.

NASCIMENTO, Lissa Crisnara Silva do. A (in) visibilidade da mulher criminosa e a desigualdade de Gênero no espaço da prisão: uma análise da vivência das mulheres em situação de prisão no complexo penal estadual agrícola $\operatorname{Dr}^{\circ}$ Mário Negócio em Mossoró/ RN. Revista Transgressões. Ciências criminais em debate, 2015. Disponível em: https://periodicos.ufrn.br/transgressoes/ 


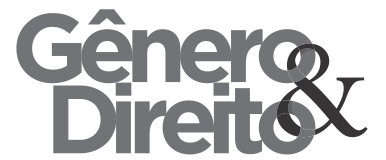

article/download/6582/5095. Acesso em: 15 jun. 2018.

NOGUEIRA, Conceição. Um novo olhar sobre as relações sociais de gênero: feminismo e perspectivas críticas na psicologia social. Fundação Calouste Gulbenkian, 2001.

NOVAES, Elizabete David; MURARI, Ana Paula. Uma reflexão teóricosociológica acerca da inserção da mulher na criminalidade. Revista Sociologia Jurídica, n. 10, jan./jun. 2010. Disponível em: https://sociologiajuridicadotnet.wordpre ss.com/uma-reflexao-teoricosociologica-acerca-da-insercao-damulher-na-criminalidade/. Acesso em: 08 jun. 2018.

OLIVEIRA, Anay Stela de; KNÖNER, Salete Farinon. A construção do conceito de gênero: uma reflexão sob o prisma da psicologia. Trabalho de Conclusão de Curso. Blumenau: FURB, 2005.

PANCIERI, Aline Cruvello. Mulheres mulas: seletividade, tráfico de drogas e vulnerabilidade de gênero. Rio de Janeiro, 2014. 99f. Monografia (Graduação em Direito) - Faculdade
Nacional de Direito, Universidade Federal do Rio de Janeiro. Disponível em:

https://www.academia.edu/11674495/M ulheres_Mulas_Seletividade_Tr\%C3\% A1fico_de_Drogas_e_Vulnerabilidade_ de_G\%C3\%AAnero. Acesso em: 18 jun. 2019.

PRAUN, Andrea Gonçalves. Sexualidade, gênero e suas relações de poder. Revista Húmus Jan/Fev/Mar/Abr. n 1. 2011. p. 55-65.

SAFFIOTI, Heleieth. Gênero, patriarcado, violência. $1^{\mathrm{a}}$ ed. São Paulo: Fundação Perseu Abramos, 2004.

SANTOS, Juliana Anacleto dos. Desigualdade social e conceito de gênero. Disponível em: http://www.ufjf.br/virtu/files/2010/05/ar tigo-3a7.pdf. Acesso em: 10 jun. 2018.

SCOTT, Joan. Gênero: uma categoria útil para análise histórica. Tradução Chistiane Rufino Debat e Maria Betânia Ávila. New York: Columbia University Press, 1989, p. 21-23. Disponível em: https://edisciplinas.usp.br/pluginfile.php /185058/mod_resource/content/2/G\%C3 
\%AAnero-Joan\%20Scott.pdf. Acesso em: 01 ago. 2018.

SOUZA, Luana Passos de; GUEDES, Dyeggo Rocha. A desigual divisão sexual do trabalho: um olhar sobre a última década. Estudos Avançados, v. 30, $\mathrm{n}^{\mathrm{o}}$ 87, 123-139. Disponível em: http://www.revistas.usp.br/eav/article/vi ew/119119. Acesso em: 12 jun. 2019 